\title{
Insolation-driven 100,000-year glacial cycles and hysteresis of ice-sheet volume
}

\author{
Ayako Abe-Ouchi, ${ }^{1,2,3}$, Fuyuki Saito ${ }^{2}$, Kenji Kawamura ${ }^{3,4}$, Maureen E. Raymo ${ }^{5}$, Jun'ichi Okuno ${ }^{1,2,3}$, Kunio Takahashi ${ }^{2}$ \\ \& Heinz Blatter ${ }^{1,6}$
}

The growth and reduction of Northern Hemisphere ice sheets over the past million years is dominated by an approximately 100,000-year periodicity and a sawtooth pattern ${ }^{1,2}$ (gradual growth and fast termination). Milankovitch theory proposes that summer insolation at high northern latitudes drives the glacial cycles $^{3}$, and statistical tests have demonstrated that the glacial cycles are indeed linked to eccentricity, obliquity and precession cycles $^{4,5}$. Yet insolation alone cannot explain the strong 100,000-year cycle, suggesting that internal climatic feedbacks may also be at work ${ }^{4-7}$. Earlier conceptual models, for example, showed that glacial terminations are associated with the build-up of Northern Hemisphere 'excess ice ${ }^{5,8-10}$, but the physical mechanisms underpinning the 100,000-year cycle remain unclear. Here we show, using comprehensive climate and ice-sheet models, that insolation and internal feedbacks between the climate, the ice sheets and the lithosphere-asthenosphere system explain the 100,000-year periodicity. The responses of equilibrium states of ice sheets to summer insolation show hysteresis ${ }^{11-13}$, with the shape and position of the hysteresis loop playing a key part in determining the periodicities of glacial cycles. The hysteresis loop of the North American ice sheet is such that after inception of the ice sheet, its mass balance remains mostly positive through several precession cycles, whose amplitudes decrease towards an eccentricity minimum. The larger the ice sheet grows and extends towards lower latitudes, the smaller is the insolation required to make the mass balance negative. Therefore, once a large ice sheet is established, a moderate increase in insolation is sufficient to trigger a negative mass balance, leading to an almost complete retreat of the ice sheet within several thousand years. This fast retreat is governed mainly by rapid ablation due to the lowered surface elevation resulting from delayed isostatic rebound ${ }^{14-16}$, which is the lithosphere-asthenosphere response. Carbon dioxide is involved, but is not determinative, in the evolution of the 100,000 -year glacial cycles.

Several internal feedback mechanisms have been suggested as crucial in 100-kyr glacial cycles, such as delayed bedrock rebound ${ }^{14-16}$, the calving of ice-sheet margins ${ }^{15}, \mathrm{CO}_{2}$ variations ${ }^{17,18}$, ocean feedback ${ }^{16}$ and dust feedback ${ }^{19,20}$. The importance of these mechanisms needs to be investigated with physical models. Here we report numerical experiments with an ice-sheet model for the Northern Hemisphere, IcIES, in combination with the general circulation model (GCM) MIROC (Methods and Supplementary Fig. 1). Although it is not practical to run GCMs with fully coupled ice-sheet models on glacial-interglacial timescales ${ }^{21}$, it is necessary to take into account the feedback from ice sheets on climate. In this study, a climate parameterization for the icesheet model is developed and calibrated using a suite of multi-snapshot atmospheric GCM experiments forced with different insolation values (for different eccentricities, obliquities and precessions), $\mathrm{CO}_{2}$ concentrations and ice-sheet sizes, calculated in advance ${ }^{22}$. The ice-sheet model with the climate parameterization (ICIES-MIROC) can represent fast feedbacks, such as water vapour, cloud and sea-ice feedbacks, and slow feedbacks, such as albedo/temperature/ice-sheet and lapserate/temperature/ice-sheet feedbacks ${ }^{22}$. We calculate the ice-sheet variation for the past $400 \mathrm{kyr}$ forced by the insolation and atmospheric $\mathrm{CO}_{2}$ content with improved dating ${ }^{23}$ after running the simulation long enough to remove the dependence on the initial conditions (Figs 1a, b; Methods). After validating these results using palaeoclimate proxy data, we conducted sensitivity experiments to investigate the mechanism of $\sim 100$-kyr glacial cycles.

Our model realistically simulates the sawtooth characteristic of glacial cycles, the timing of the terminations and the amplitude of the Northern Hemisphere ice-volume variations (Fig. 1d) as well as their geographical patterns at the Last Glacial Maximum and the subsequent deglaciation (Supplementary Figs 2 and 3 and Supplementary Video 1). In the frequency domain, our model produces the largest spectral peak at a periodicity of $\sim 100 \mathrm{kyr}$, as observed in the data (Fig. 1), even without the ocean feedback ${ }^{16}$ or dust feedback ${ }^{19}$. In a series of model experiments, we investigated the roles of $\mathrm{CO}_{2}$ (which also varies with a 100-kyr periodicity; Fig. 1b), various model parameters such as the time constant and the effective mantle density for isostatic rebound, and mass loss due to calving into proglacial lakes. The $\sim 100$-kyr periodicity, the sawtooth pattern and the timing of the terminations are reproduced with constant $\mathrm{CO}_{2}$ levels ${ }^{20,24}$ (for example 220 p.p.m.; Fig. 1e), and are robust for a range of model parameters (Supplementary Fig. 4).

By contrast, the spectral peak of $\sim 100$-kyr cycles is greatly reduced, and permanent large ice sheets remain, with the imposition of instantaneous isostatic rebound (Fig. 1f). This result supports the idea that the crucial mechanism for the $\sim 100$-kyr cycles is the delayed glacial isostatic rebound ${ }^{14,15}$, which keeps the ice elevation low, and, therefore, the ice ablation high, while the ice sheet retreats. We note, however, that $\mathrm{CO}_{2}$ variations can result in amplification of the full magnitude of ice-volume changes during the $\sim 100$-kyr cycles, but do not drive the cycles. Ice-sheet changes may induce variations in $\mathrm{CO}_{2}$ through changing sea surface temperature, affecting the solubility of $\mathrm{CO}_{2}$ (ref. 25), and through changing sea level, affecting the stratification of and $\mathrm{CO}_{2}$ storage in the Southern Ocean ${ }^{18}$. During deglaciation, the melt water may affect ocean circulation, leading to an increase in atmospheric $\mathrm{CO}_{2}$ (refs 23, 26, 27).

A striking feature of our results is that, in the experiments with constant $\mathrm{CO}_{2}$ levels, the strong $\sim 100$-kyr cycle with a large amplitude appears only for the North American ice sheet within a particular range of $\mathrm{CO}_{2}$ levels; the spectral peak of $\sim 100$-kyr cycle becomes small compared with those of $\sim 41$ and $\sim 23$-kyr cycles for $\mathrm{CO}_{2}$ levels above 230 p.p.m. or below 190 p.p.m. (Fig. 1g). The Eurasian ice sheet responds only to insolation forcings at $\sim 41$-kyr and $\sim 23$-kyr periodicities, with small amplitudes in all cases (Fig. 1h). To investigate the mechanisms behind these observations, we conducted 200-kyr model experiments to obtain stable equilibria of both ice sheets for a range of prescribed climatic forcings, starting from either no ice or from large

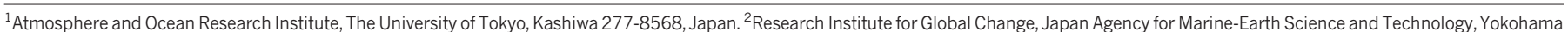

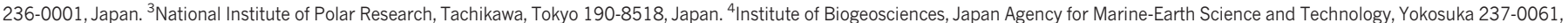
Japan. ${ }^{5}$ Lamont-Doherty Earth Observatory, Columbia University, Palisades, New York 10964, USA. ${ }^{6}$ Institute for Atmospheric and Climate Science, ETH Zurich, CH-8092 Zurich, Switzerland. 
ice sheets; we use summer temperature anomalies ranging from -5 to $+3 \mathrm{~K}$ relative to the present day.

Because of strong albedo and topographic feedbacks, ice sheets are expected to have multiple stable equilibria ${ }^{11-13}$. We indeed observe two different equilibrium states for a range of climatic forcings, depending on the initial size of the ice sheets. Figure 2a shows maps of the equilibrium ice sheets and their corresponding surface mass balances, for various climate forcings, computed with large initial ice sheets. We also show the equilibrium volumes of the North American and Eurasian ice sheets versus the climate forcing (Fig. 2b), which both have hysteresis loops but with different shapes. For each ice sheet, the lower and upper branches in the ice-volume hysteresis loop (Fig. 2b, blue and red lines) correspond to equilibrium states resulting from small and large initial

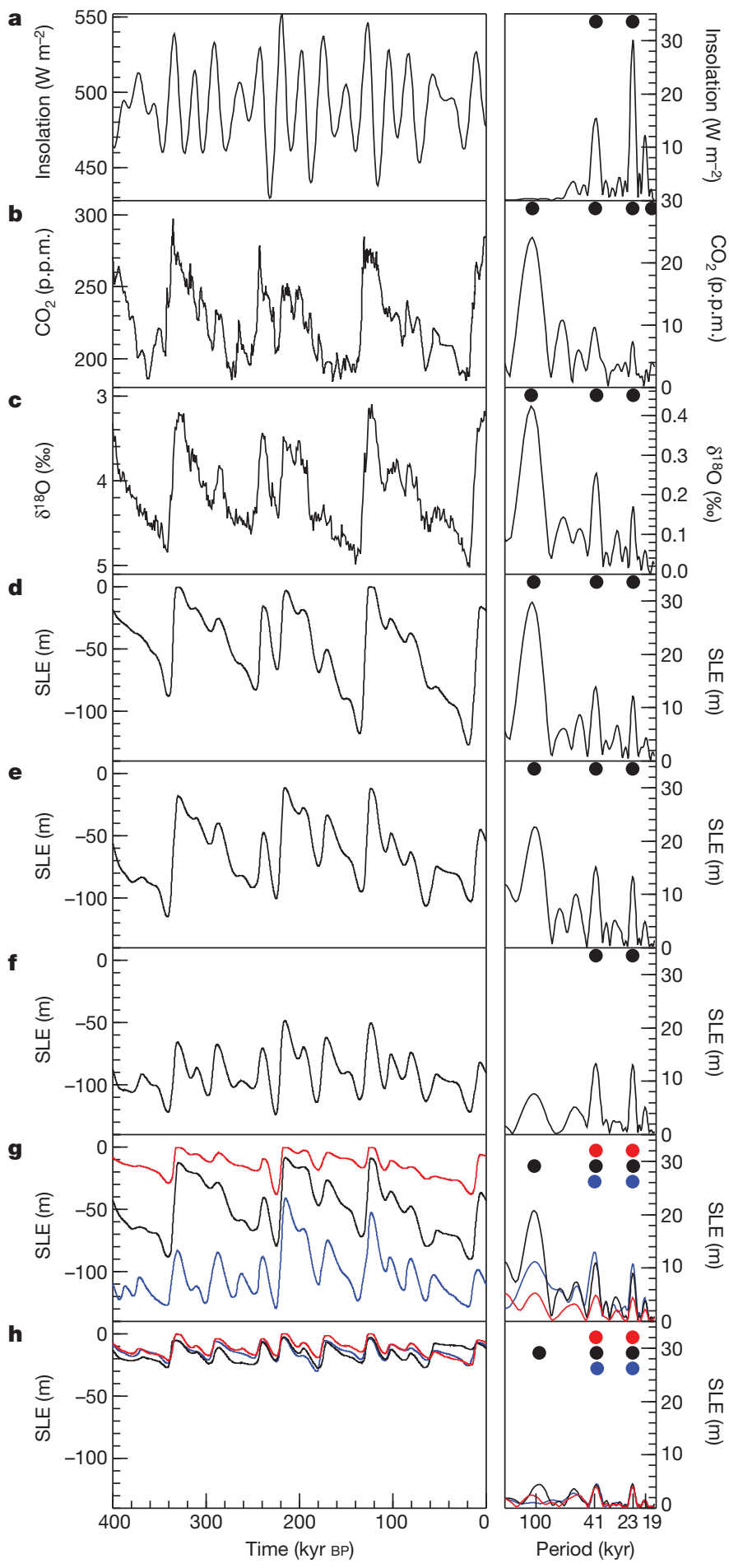

states, respectively. The hysteresis branches define the ice-sheet states with neutral (equilibrium) mass balance for a given climatic forcing; the ice-sheet gains (or loses) mass if the climatic forcing falls below the lower branch (or rises above the upper branch). Crucially, the larger the ice sheet becomes, the smaller the forcing required for negative mass balance, as is reflected in the inclination of the upper branch. The positions and shapes of the hysteresis loops, and especially the inclinations of the upper branches, are quite different for the two ice sheets. The equilibrium states on the upper hysteresis branch of the North American ice sheet vary gradually over a wider range of forcings, from -2 to $+2 \mathrm{~K}$, relative to those of the Eurasian ice sheet, which range from -2 to $-1 \mathrm{~K}$ (Fig. $2 \mathrm{a}, \mathrm{b}$ ).

To identify the physical mechanisms causing $\sim 100$-kyr cycles, we compare the results of equilibrium states with the simulated transient ice volume of the standard case with varying insolation and $\mathrm{CO}_{2}$ forcings for the most recent glacial cycle (Fig. 1d); these data are plotted together in Fig. 2b. To enable the comparison, we converted insolation and $\mathrm{CO}_{2}$ forcings to the summer temperature anomaly ${ }^{22}$ (Methods). For the North American ice sheet, starting from the last interglacial forcing, $122 \mathrm{kyr}$ before present (BP), with no ice, a rapid decrease in insolation well below the lower branch forces the mass balance to become positive and large, triggering the inception and growth of the ice sheet from the Canadian high Arctic, around latitude $70^{\circ} \mathrm{N}$, to Labrador. Although the summer insolation maxima are large for the first two precessional cycles because of large eccentricity (104 and 84 kyr BP; Fig. 2b), the mass balance becomes negative only for a few thousand years because the upper hysteresis branch extends to high forcing values for small volumes.

As the ice sheet grows, the insolation forcing required for negative mass balance gradually becomes smaller. However, the reduction in eccentricity also makes the subsequent insolation maxima smaller, so the ice sheet continues to experience mostly a positive or near-neutral mass balance. By the fifth precession minimum ( $24 \mathrm{kyr}$ вP) since the most recent interglacial period, near the eccentricity minimum, the volume of the North American ice sheet reaches nearly $90 \mathrm{~m}$ sea-level equivalent (that is, a volume equivalent to a change of $90 \mathrm{~m}$ in global sea level). At this stage, the southern margin of the large ice sheet is warm enough that a moderate climatic forcing can cause the ice sheet to retreat. With the subsequent increase in eccentricity, the summer insolation forcing in the next precessional cycle provides enough time and intensity for a rapid disintegration of the ice sheet (note the large excursion of insolation forcing above the upper hysteresis branch; Fig. 2b), which is why a large ice volume, called 'excess $100-\mathrm{kyr}$ ice ${ }^{8}$, is observed before each glacial termination.

The upper branch in our hysteresis loop defines the threshold in ice volume and insolation at which the switch from a glacial state to a deglacial state occurs. Whereas the growth rate is governed by the gradual accumulation of snow, the retreat rate is governed by highly nonlinear processes such as the large ablation of ice that results from

Figure $1 \mid$ Time series of forcing and responses of Northern Hemisphere ice sheets. Left, time series of the past $400 \mathrm{kyr}$; right, corresponding spectra. a, Mean extra-atmospheric insolation at latitude $65^{\circ} \mathrm{N}$ on 21 June of each year, which closely corresponds to the summer solstice. b, Atmospheric $\mathrm{CO}_{2}$ from Vostok ice core on a revised timescale (ref. 23 and references therein). c, $\delta^{18} \mathrm{O}$ from benthic foraminifera as a proxy for sea level and deep ocean temperature ${ }^{30}$. d, Modelled sea-level equivalent (SLE) of ice-volume changes relative to present with variations in atmospheric $\mathrm{CO}_{2}$ content and insolation (standard case). e, Same as $\mathbf{d}$ but with a constant $\mathrm{CO}_{2}$ concentration of 220 p.p.m. f, Same as e but with instant isostatic rebound. g, Same as $\mathbf{d}$ but with different constant $\mathrm{CO}_{2}$ concentrations (blue, 160 p.p.m.; black, 220 p.p.m.; red, 260 p.p.m.) for the North American ice sheet. h, Same as $\mathbf{g}$ but for the Eurasian ice sheet. The spectra (right) show the amplitudes (calculated by the Multi-Taper Spectral Analysis Methods (MTM); using Analy Series; http://www.lsce.ipsl.fr/logiciels/index.php) in the corresponding frequencies of the time series (left). The coloured dots indicate peaks with more than $95 \%$ significance for the corresponding coloured curves. 


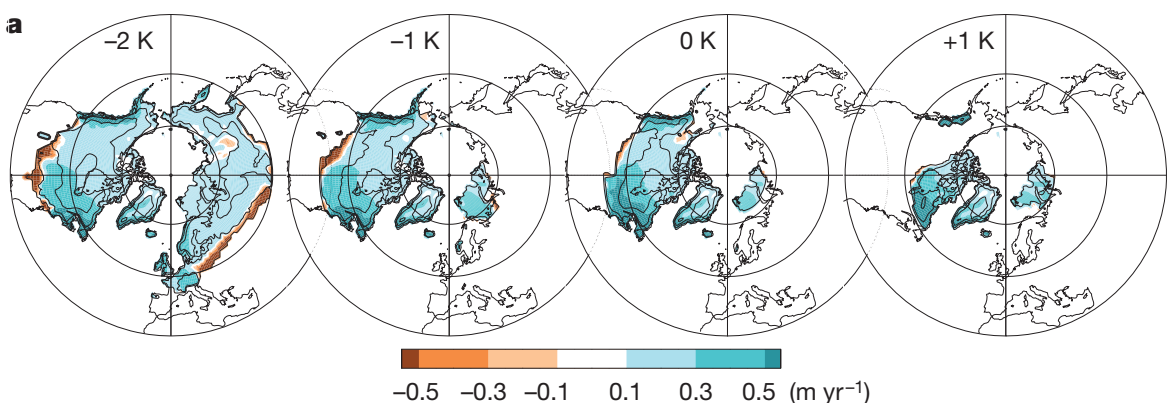

b
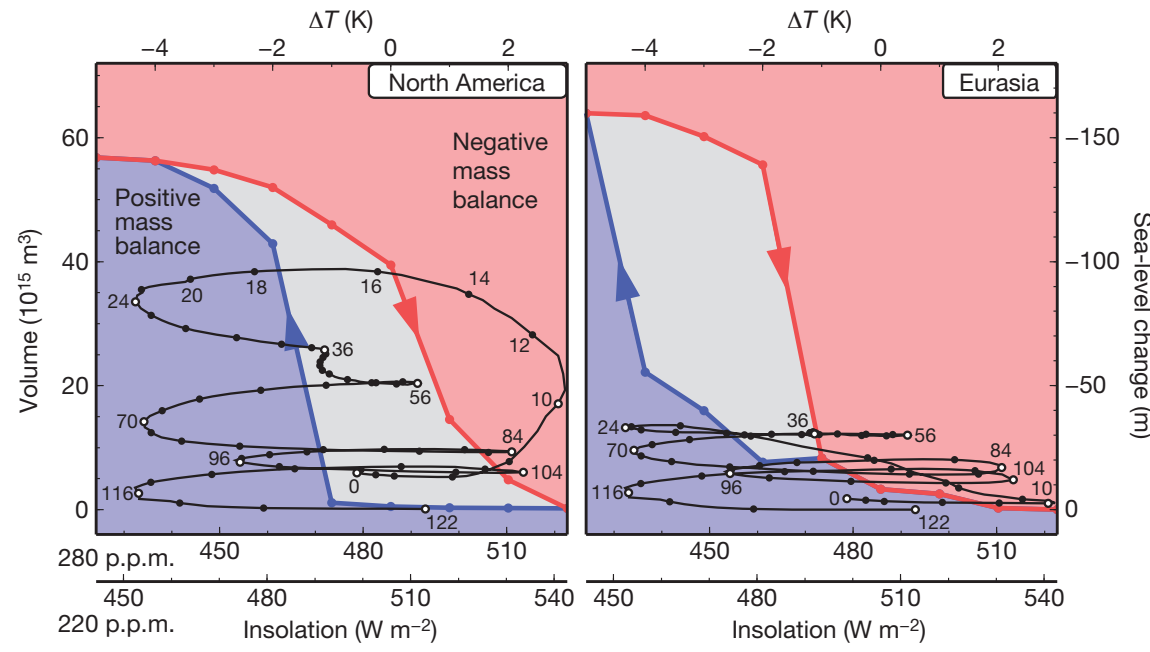

c
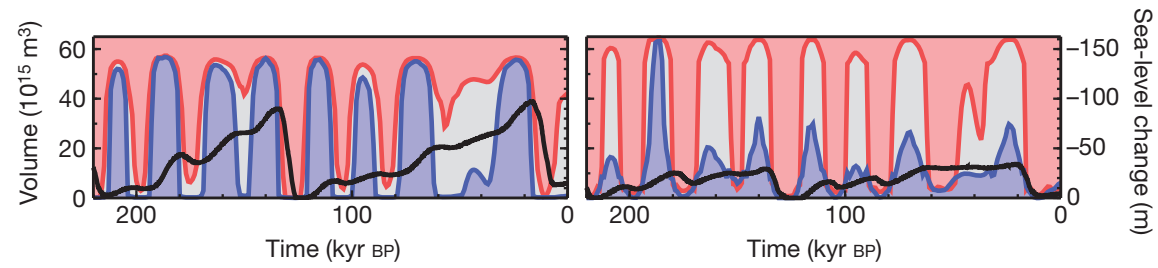

Figure $2 \mid$ Hysteresis of equilibrium states and transient evolution of the Northern Hemisphere ice sheets. a, Maps showing the equilibrium shapes and surface mass balances of ice sheets when the climatic anomalies relative to present conditions are respectively (left to right) $-2,-1,0$ and $1 \mathrm{~K}$ (summer temperature) and when the model runs start from large initial ice sheets. Colours indicate the surface mass balance in metres per year. Note the large ablation areas and ablation rates (negative mass balance) that appear in the warm low latitudes. b, Modelled equilibrium and transient ice volumes as functions of the summer temperature anomaly for the North American (left) and Eurasian (right) ice sheets: red dots denote the large-volume equilibrium states if the model runs start from large initial ice sheets; blue dots show the small-volume equilibrium states for small initial ice sheets. The blue areas indicate a positive total mass balance of the ice sheet; red areas indicate a negative total mass balance. The black dots mark the evolution of the transient ice volume every $2 \mathrm{kyr}$ for the last glacial cycle starting $122 \mathrm{kyr}$ BP. The small numbers on the black trajectories show the corresponding time in kiloyears. The horizontal scales below the figures show the relation between the temperature anomaly (Methods) and the corresponding insolation at latitude $65^{\circ} \mathrm{N}$ on 21 June for two given constant atmospheric $\mathrm{CO}_{2}$ concentrations (220 p.p.m. and 280 p.p.m.). c, Same as b but data shown as time series for the past two glacial cycles. the low surface elevation due to the delayed isostatic response. Other processes may enhance the fast retreat, such as calving into proglacial lakes (Supplementary Fig. 2), increasing $\mathrm{CO}_{2}$ concentrations, dust feedback ${ }^{20}$, vegetation feedback ${ }^{28}$ and basal sliding ${ }^{29}$.

In contrast to the North American ice sheet, the dominant cycle of the volume of the Eurasian ice sheet has a period of $\sim 40 \mathrm{kyr}$, and the volume never grows beyond $40 \mathrm{~m}$ sea-level equivalent. This pattern occurs for two reasons. First, the hysteresis branches of the ice volume are located within the lower half of the range of possible forcing variations (Fig. 2b). Thus, the ice sheet loses mass for a long time during insolation cycles. The difference in the positions of the hysteresis branches stems from the summers being generally warmer over Eurasia than over North America at high latitudes. Second, and more fundamentally, the upper hysteresis branch shows a step change, similar to that which occurs over Antarctica ${ }^{13}$, whereby the volume decreases by $120 \mathrm{~m}$ sealevel equivalent for an increase in climatic forcing of only $1 \mathrm{~K}$. Thus, regardless of the mean climatic state, the Eurasian ice sheet would not show $\sim 100-\mathrm{kyr}$ cycles because it cannot sustain intermediate ice volumes under the widely varying summer insolation forcing (equivalent to $6 \mathrm{~K}$ in a precessional cycle); the ice sheet can be only very large or very small (not shown). In summary, the shape and position of the hysteresis curve, different for each continent and for different constant $\mathrm{CO}_{2}$ levels, are important in determining whether the dominant climatic cycle is $\sim 100 \mathrm{kyr}$ or $\sim 40 \mathrm{kyr}$ in period.

The ice sheets behave as a dynamical system: an ice sheet tends to approach a stable equilibrium state that also changes with time as the climatic forcing changes. This behaviour is illustrated in Fig. 2c, which shows the time series of the volume evolution (black lines) and the attracting steady states (blue and red lines) corresponding to the hysteresis branches in Fig. 2b. Points where the stable equilibrium state lines cross correspond to changes in the sign of the mass balance and, thus, to changes between growing and shrinking ice sheets. The different timescales for growth $\left(\sim 10^{4} \mathrm{yr}\right)$ and decay $\left(\sim 10^{3} \mathrm{yr}\right)$ result in the decreases in volume evolution (Fig. 2c, black curves) to be much steeper than the increases. This asymmetry ultimately explains the characteristic sawtooth shape of the glacial cycles.

To understand the relative importance of the three astronomical parameters in generating the $\sim 100$-kyr cycles of the North American ice sheet, we conducted model experiments in which we kept fixed the eccentricity, obliquity or precession in turn, under a constant $\mathrm{CO}_{2}$ concentration of 220 p.p.m. Results show that the $\sim 100-\mathrm{kyr}$ cycles persist for fixed obliquity, but not for fixed eccentricity or for fixed precession (Fig. 3 and Supplementary Fig. 6). These results demonstrate the essential role of precession and the eccentricity variation for the $\sim 100$-kyr cycle. Obliquity is not the driver of the $\sim 100$-kyr cycle, although it helps to amplify the ice-volume changes from glacial states to interglacial states. In summary, our model results suggest that the $\sim 100$-kyr cycle is essentially produced by the eccentricity modulation of precession amplitude through the changes in summer insolation ${ }^{8}$, with the support of obliquity for glacial terminations, especially when eccentricity remains small after its minimum (for example at termination I 20-10 kyr BP and at termination IV 340-330 kyr BP). 


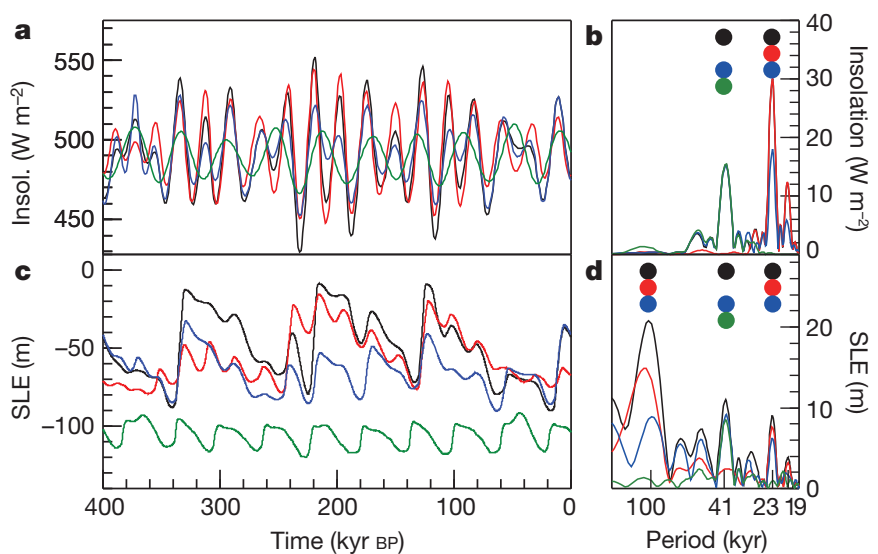

Figure $3 \mid$ Role of eccentricity, obliquity and precession in the 100-kyr cycle. Time series of the model experiments with one of eccentricity, obliquity or precession fixed for a constant atmospheric $\mathrm{CO}_{2}$ concentration of 220 p.p.m. a, Insolation forcing (insolation at latitude $65^{\circ} \mathrm{N}$ on 21 June) with variations in eccentricity, obliquity and precession (black lines); with obliquity fixed at $23.5^{\circ}$ (red lines); with eccentricity fixed at 0.02 (blue lines); and with perihelion passage fixed at the spring equinox and no precession (green lines).

b, Corresponding spectra of insolation change in a (as in Fig. 1a). c, Calculated ice-volume change, expressed as sea-level equivalent (colours same as in a). d, Corresponding spectra of calculated ice-volume change in $\mathbf{c}$ (as in Fig. 1d).

A remarkable conclusion from our model results is therefore that the 100-kyr glacial cycle exists only because of the unique geographic and climatological setting of the North American ice sheet with respect to received insolation. Only for the North American ice sheet is the upper hysteresis branch moderately inclined; that is, there is a gradual change between large and small equilibrium ice-sheet volumes over a large range of insolation forcings. For this reason, as demonstrated in Fig. 2b, the amplitude modulation of summer insolation variation in the precessional cycle, due primarily to eccentricity, is able to generate the 100-kyr cycles with large amplitude, gradual growth and rapid terminations.

\section{METHODS SUMMARY}

A climate parameterization, taking into account the relevant climatic factors that control the ice-sheet evolution, is obtained from a suite of experiments using the MIROC GCM. On the basis of this climate parameterization, we drive the thermomechanically coupled shallow-ice-sheet model IcIES to study the impact of insolation and atmospheric $\mathrm{CO}_{2}$ content on the change of Northern Hemisphere ice sheets. The experimental methods using the IcIES-MIROC model follow ref. 22 with a few modifications, as follows. The interaction between ice-sheet volume/area and the surface temperature is composed of the lapse-rate and albedo effects, and, as a novel term, the stationary-wave feedback, which is expressed as a spatial pattern of a temperature anomaly determined by GCM runs, weighted by a factor that depends on the ice-covered area over North America. The modifications in the ice sheet model concern the parameterization for basal sliding over the sediment and hard rock, which uses a realistic map of sediment thickness; the calving parameterization at the margin in terms of prescribed grounding-line flux; and the parameters in the isostatic rebound scheme, which are optimized by using a coupled ice-sheet/lithosphere/asthenosphere model.

Full Methods and any associated references are available in the online version of the paper.

\section{Received 19 February; accepted 10 June 2013.}

1. Clark, P. U. et al. The Last Glacial Maximum. Science 325, 710-714 (2009).

2. Hays, J. D., Imbrie, J. \& Shackleton, N. J. Variations in Earth's orbit - pacemaker of ice ages. Science 194, 1121-1132 (1976).

3. Milankovitch, M. Kanon der Erdbestrahlung und seine Anwendung auf das Eiszeitproblem (R. Serbian Acad., 1941)

4. Lisiecki, L. E. Links between eccentricity forcing and the 100,000-year glacial cycle. Nature Geosci. 3, 349-352 (2010).
5. Huybers, P. Combined obliquity and precession pacing of late Pleistocene deglaciations. Nature 480, 229-232 (2011).

6. Saltzman, B., Hansen, A. R. \& Maasch, K. A. The late Quaternary glaciations as the response of a three-component feed back system to Earth-orbital forcing. J. Atmos. Sci. 41, 3380-3389 (1984)

7. Tziperman, E., Raymo, M. E., Huybers, P. \& Wunsch, C. Consequences of pacing the Pleistocene 100 kyr ice ages by nonlinear phase locking to Milankovitch forcing. Paleoceanography 21, PA4206 (2006)

8. Raymo, M. E. The timing of major climate terminations. Paleoceanography $\mathbf{1 2}$ 577-585 (1997).

9. Paillard, D. The timing of Pleistocene glaciations from a simple multiple-state climate model. Nature 391, 378-381 (1998).

10. Parrenin, F. \& Paillard, D. Amplitude and phase of glacial cycles from a conceptual model. Earth Planet. Sci. Lett. 214, 243-250 (2003).

11. Abe-Ouchi, A. \& Blatter, H. On the initiation of ice sheets. Ann. Glaciol. 18, 203-207 (1993).

12. Calov, R. \& Ganopolski, A. Multistability and hysteresis in the climate-cryosphere system under orbital forcing. Geophys. Res. Lett. 32, L21717 (2005).

13. Pollard, D. \& DeConto, R. M. Hysteresis in Cenozoic Antarctic ice-sheet variations. Global Planet. Change 45, 9-21 (2005).

14. Oerlemans, J. Model experiments on the 100,000-yr glacial cycle. Nature $\mathbf{2 8 7}$ 430-432 (1980)

15. Pollard, D. A simple ice-sheet model yields realistic $100 \mathrm{kyr}$ glacial cycles. Nature 296, 334-338 (1982)

16. Deblonde, G., Peltier, W. R. \& Hyde, W. T. Simulations of continental ice sheet growth over the last glacial-interglacial cycle: experiments with a one level seasonal energy balance model including seasonal ice albedo feedback. Palaeogeogr. Palaeoclimatol. Palaeoecol. 98, 37-55 (1992).

17. Shackleton, N. J. The 100,000-year ice-age cycle identified and found to lag temperature, carbon dioxide, and orbital eccentricity. Science 289, 1897-1902 (2000).

18. Paillard, D. \& Parrenin, F. The Antarctic ice sheet and the triggering of deglaciations. Earth Planet. Sci. Lett. 227, 263-271 (2004).

19. Peltier, W. R. \& Marshall, S. Coupled energy-balance ice-sheet model simulations of the glacial cycle: a possible connection between terminations and terrigenous dust. J. Geophys. Res. 100, 14269-14289 (1995)

20. Ganopolski, A. \& Calov, R. The role of orbital forcing, carbon dioxide and regolith in 100 kyr glacial cycles. Clim. Past 7, 1415-1425 (2011).

21. Gregoire, L. J., Payne, A. J. \& Valdes, P. J. Deglacial rapid sea level rises caused by ice-sheet saddle collapses. Nature 487, 219-222 (2012).

22. Abe-Ouchi, A., Segawa, T. \& Saito, F. Climatic conditions for modelling the Northern Hemisphere ice sheets throughout the ice age cycle. Clim. Past 3, 423-438 (2007)

23. Kawamura, K. et al. Northern Hemisphere forcing of climatic cycles in Antarctica over the past 360,000 years. Nature 448, 912-916 (2007)

24. Berger, A., Loutre, M. F. \& Gallee, H. Sensitivity of the LLN climate model to the astronomical and CO2 forcings over the last 200 ky. Clim. Dyn. 14, 615-629 (1998).

25. Kurahashi-Nakamura, T.,Abe-Ouchi, A. \& Yamanaka, Y. Effects of physical changes in the ocean on the atmospheric $\mathrm{pCO}_{2}$ : glacial-interglacial cycles. Clim. Dyn. 35, 713-719 (2009).

26. Ganopolski, A.\& Roche, D. M. On the nature of lead-lag relationships during glacialinterglacial climate transitions. Quat. Sci. Rev. 28, 3361-3378 (2009).

27. He, F. et al. Northern Hemisphere forcing of Southern Hemisphere climate during the last deglaciation. Nature 494, 81-85 (2013).

28. Claussen, M., Fohlmeister, J., Ganopolski, A. \& Brovkin, V. Vegetation dynamics amplifies precessional forcing. Geophys. Res. Lett. 33, L09709 (2006).

29. Marshall, S. J. \& Clark, P. U. Basal temperature evolution of North American ice sheets and implications for the 100-kyr cycle. Geophys. Res. Lett. 29, 2214 (2002)

30. Lisiecki, L. E. \& Raymo, M. E. A. Pliocene-Pleistocene stack of 57 globally distributed benthic $\delta^{18} 0$ records. Paleoceanography 20, PA1003 (2005).

Supplementary Information is available in the online version of the paper.

Acknowledgements Discussions with numerous people including M. Kimoto, J. Hargreaves, M. Yoshimori, J. Annan, F.-F. Jin and W.-L. Chan contributed to this work M. Ichino and T. Segawa provided technical support. We thank the MIROC group for continuous development and support of the MIROC GCM. The numerical experiments were carried out on the NIES supercomputer system (NEC SX-8R/128M16) and the JAMSTEC Earth Simulator. This research was supported by JSPS KAKENHI grants 25241005,22101005 and 21671001, the Global COE Program grant "From the Earth to 'Earths"', MEXT, Japan, and the Environment Research and Technology Development Fund (S-10) of the Ministry of the Environment, Japan.

Author Contributions A.A.-O. designed the research and experiments, and wrote the manuscript with F.S., K.K., M.E.R. and H.B. A.A.-O. and F.S. developed the numerical model, performed the experiments and analysed the results with K.T., K.K. and H.B. K.K. provided the ice-core data, and J.O. provided the Earth model for glacial isostatic rebound. All authors discussed the results and provided inputs on the manuscript.

Author Information Reprints and permissions information is available at www.nature.com/reprints. The authors declare no competing financial interests. Readers are welcome to comment on the online version of the paper. Correspondence and requests for materials should be addressed to A.A.-O.

(abeouchi@aori.u-tokyo.ac.jp). 


\section{METHODS}

IcIES-MIROC model. The IcIES-MIROC model used in this study corresponds to the one described in ref. 22, with a few modifications explained below. The climate factors that control the ice-sheet changes, such as lapse rate and albedo feedback, are obtained from a suite of experiments using discrete GCM snapshots to obtain a climate parameterization ${ }^{31}$. On the basis of this climate parameterization, we drive the ice-sheet model to study the impact of orbital parameters and atmospheric $\mathrm{CO}_{2}$ content on the change of Northern Hemisphere ice sheets.

Climate parameterization. To examine the response of climate to the orbital parameters, $\mathrm{CO}_{2}$ and ice sheets, the atmospheric part of the atmosphere-ocean coupled GCM MIROC is used (K-1 developers, The University of Tokyo, 2004; http://ccsr.aori.u-tokyo.ac.jp/ hasumi/miroc_description.pdf). The model resolutions used in the present study are $\mathrm{T} 106\left(1^{\circ}\right.$ latitude, $1^{\circ}$ longitude $)$ and 20 vertical sigma levels with $\sim 50$-m thickness near the ice-sheet surface, and T42 with 11 levels, as in table 1 in ref. 22. The model includes dynamical and physical processes such as radiative transfer and high-resolution boundary-layer physics, which are necessary to resolve processes crucial for modelling the ice-sheet/climate system of the glacial cycles.

From the set of 18 sensitivity experiments with MIROC $^{22}$, including PMIP (Paleoclimate Modelling Intercomparison Project) experiments ${ }^{32}$, the climatic effects of the changes in orbital parameters, atmospheric $\mathrm{CO}_{2}$ content, lapse rate and surface albedo are separated and parameterized as follows:

$$
T_{s}=T_{\text {ref }}+\Delta T_{\text {sol }}+\Delta T_{\mathrm{CO}_{2}}+\Delta T_{\text {ice }}+\Delta T_{\text {nonlinear }}
$$

Here $T_{\mathrm{s}}$ is the surface temperature and $T_{\text {ref }}$ is a reference temperature based on the present-day climatology of the European Centre for Medium-Range Weather Forecasts (ECMWF)/ERA-40 meteorological re-analysis data (http://www.ecmwf. int/research/era/do/get/era-40). The terms $\Delta T_{\mathrm{CO}_{2}}$ and $\Delta T_{\text {sol }}$ denote the changes in temperature according to changes in atmospheric $\mathrm{CO}_{2}$ content and the change in temperature according to changes in insolation, respectively. The term $\Delta T_{\text {nonlinear }}$ is a residual term due to other feedback effects. The effects of the atmospheric response to changes in ice-sheet size, $\Delta T_{\text {ice }}$, is decomposed into three terms

$$
\Delta T_{\text {ice }}=\Delta T_{\text {lapse }}+\Delta T_{\text {albedo }}+\Delta T_{\text {swf }}
$$

where the lapse-rate effect depends on the local surface elevation, the albedo effect depends on the ice-sheet size and the stationary-wave feedback of the atmosphere, $\Delta T_{\text {swf }}$. The stationary-wave feedback is prescribed in the model runs by a temperature map, where the lapse-rate effect is subtracted from the difference between a model experiments with full ice-sheet topography and a model experiment with only flat ice, but both with ice albedo. It is expressed as a product of a spatial pattern of the temperature anomaly and a factor, $r$, that depends on the ice-covered area over North America:

$$
r=\max \left[0, \min \left[1, \frac{A(t)-A_{12 \mathrm{kyr}}}{A_{\max }-A_{12 \mathrm{kyr}}}\right]\right]
$$

Here $A_{12 \mathrm{kyr}}=8.146818 \times 10^{12} \mathrm{~m}^{2}$ and $A_{\max }=1.4 \times 10^{13} \mathrm{~m}^{2}$ are the assumed icecovered area over North America $12 \mathrm{kyr} B \mathrm{P}$ and at the Last Glacial Maximum, respectively.

The parameterization of the effect of variable astronomical forcing and variable $\mathrm{CO}_{2}$ follows that of ref. 22. For surface melt on the ice sheet, a positive-degree-day scheme following ref. 33 is applied. The astronomical forcing is based on ref. 34 , and the $\mathrm{CO} 2$ forcing $^{35}$ is modified with revised dating ${ }^{23}$.

IcIES ice-sheet model. The numerical ice-sheet model used in this study is the icesheet model for integrated Earth-system studies (IcIES), which is a thermomechanically coupled model in the shallow-ice approximation. The model is driven by surface boundary conditions such as the distributed temporal variations of climate in terms of surface mass balance and temperature, and by basal boundary conditions such as the bed topography, fixed geothermal heat flux and fixed sediment/ hard-rock distribution. Sensitivity studies on model parameters and initial conditions are shown in Supplementary Figs 2, 4 and 5. The model modifications compared with ref. 22 are as follows.

(1) Basal sliding. The parameterization for basal sliding over the sediment and hard-rock follows ref. 36. The grid points are categorized as either sediment type or hard-rock type. A sliding law of the form $u_{\mathrm{b}}=C H|\nabla h|^{n} \nabla h$ is used, where $u_{\mathrm{b}}$ is the sliding velocity, $H$ is the local ice thickness, $\nabla h$ is the surface inclination and $C$ is the sliding coefficient. For the sediment-type grid points we use a linear sliding law with $C=500 \mathrm{yr}^{-1}$ and $n=0$, whereas for hard-rock-type grid points a nonlinear sliding law with $C=10^{5} \mathrm{yr}^{-1}$ and $n=2$ is used. To prescribe the sediment area in the ice-sheet model, a global map of sediment thickness at a resolution of $1^{\circ}$ by $1^{\circ}$ provided by SEDMAP ${ }^{37}$ is used. If the sediment thickness is more than $100 \mathrm{~m}$, then sediment-type basal sliding is applied; otherwise, hard-rock-type sliding is applied.

(2) Calving. In addition to the passive calving at the margin of the land $\mathrm{d}^{22}$ (defined by a prescribed land mask), a parameterization of active calving ${ }^{38}$ is implemented to represent a potential marine ice-sheet instability ${ }^{39}$. The calving flux (acting as grounding-line flux) at the margin is applied if a grid point satisfies the following three conditions: the bedrock elevation at the grid point is below sea level, corresponding to a marine ice-sheet situation; the surface mass balance at the grid point is negative, corresponding to an ablation area; and the grid faces the ocean, that is, at least one of the eight neighbouring grid points satisfies the floating condition. We apply a constant calving flux by replacing the surface ablation on this grid point by a fixed value $\left(-10 \mathrm{~m} \mathrm{yr}^{-1}\right.$ in the standard run).

(3) Isostatic rebound. The dynamics of isostatic rebound is given by ${ }^{22}$

$$
\frac{\partial b}{\partial t}=-\frac{1}{\tau}\left[b-b_{0}+\frac{\rho_{\mathrm{i}}}{\rho_{\text {eff }}} H\right]
$$

where $b, b_{0}, H, t$ and $\rho_{\mathrm{i}}$ are the transient bed elevation, the relaxed bed elevation without ice load, the ice thickness, time and the ice density, respectively. We introduce an effective mantle density of $\rho_{\text {eff }}=4,500 \mathrm{~kg} \mathrm{~m}^{-3}$ and a time constant of $\tau=5,000 \mathrm{yr}$ in the present study (Supplementary Figs 2 and 4). The high effective density and the time constant are optimized using the viscoelastic Earth model of ref. 40 coupled to the IcIES ice-sheet model ${ }^{41}$. The high effective density compensates for the missing elastic forces in Earth's crust, which reduce the total isostatic motion ${ }^{42}$.

31. Pollard, D. A retrospective look at coupled ice sheet-climate modeling. Clim. Change 100, 173-194 (2010).

32. Braconnot, P. et al. Evaluation of climate models using palaeoclimatic data. Nature Clim. Change 2, 417-424 (2012).

33. Reeh, N. Parameterization of melt rate and surface temperature on the Greenland ice sheet. Polarforschung 59, 113-128 (1991).

34. Berger, A. L. Long-term variations of daily insolation and quaternary climatic changes. J. Atmos. Sci. 35, 53-74 (1978).

35. Petit, J. R. etal. Climate and atmospheric history of the past 420,000 years from the Vostok ice core, Antarctica. Nature 399, 429-436 (1999).

36. Calov, R., Ganopolski, A., Petoukhov, V., Claussen, M. \& Greve, R. Large-scale instabilities of the Laurentide ice sheet simulated in a fully coupled climate-system model. Geophys. Res. Lett. 29, 2216 (2002).

37. Laske, G. \& Masters, G. A global digital map of sediment thickness. Eos Trans. AGU 78, F483 (1997).

38. Pollard, D. in Milankovitch and Climate: Understanding the Response to Astronomical Forcing Pt 2 (eds Berger, A., Imbrie, J., Hays, H., Kukla, G. \& Saltzman, B.) 541-564 (Reidel, 1984).

39. Pollard, D. \& DeConto, R. M. Modelling West Antarctic ice sheet growth and collapse through the past five million years. Nature 458, 329-332 (2009).

40. Okuno, J. \& Nakada, M. Effects of water load on geophysical signals due to glacial rebound and implications for mantle viscosity. Earth Planets Space 53, 1121-1135 (2001).

41. Okada, Y. Interaction between Northern Hemisphere Ice Sheet and Solid Earth Throughout the Ice Age Cycle [in Japanese]. MSc thesis, Univ. Tokyo (2008),

42. Crucifix, M., Loutre, M. F., Lambeck, K. \& Berger, A. Effect of isostatic rebound on modelled ice volume variations during the last 200 kyr. Earth Planet. Sci. Lett. 184, 623-633 (2001). 